\title{
An interactive approach for the design of an Italian fast medical support ship as consequence of world emergency due to Sars2-Covid 19
}

\author{
Valerio Ruggiero $^{1}$ (D) $\cdot$ Eugenio Guglielmino ${ }^{1}$ (D) $\cdot$ Filippo Cucinotta $^{1}$ (D)
}

Received: 17 April 2020 / Accepted: 22 January 2022 / Published online: 5 February 2022

( $)$ The Author(s), under exclusive licence to Springer-Verlag France SAS, part of Springer Nature 2022

\begin{abstract}
In spring 2020 we faced a completely new type of world crisis due to the spread, all around the world, of a pandemic disease due to a new type of coronavirus. Basically all the countries in the world are having to deal with the need to offer medical aid to the people with symptoms, and the particular type of medical treatments is causing serious problems to the hospitals, basically blocking also or slowing the capability to assist other pathologies or diseases or needs. In all those situations what is basically needed is the capability to fulfill the request of: a quick help, the transport of materials for med aids, the transport of mechanized tools for police missions and/or support to populations. A ship capable to move quickly to a port to increase local hospital capacity could be an important help. Countries like the USA already have a large experience in hospital ships or support ships, in Italy a solution has been arranged converting a ferry into a hospital ship to support less dangerous causes or other needs. Starting from these considerations the authors have investigated the possibility to realize a refitting of an existing unit to realize a ship capable to give a partial assistance in those situations. Key of the project is the interactivity between re-design and use of an existing ship to obtain a result in short time. Examining the main characteristics suitable for a ship with this aim, the authors made a critical examination of the state of the art of the ships for support and assistance, considering the various available solutions, and then made a study of the customization of a ship summarizing all those aspects, with an operational speed of above 35 knots if required, with an interactive approach at new design between naval architecture and medical/support aspects.
\end{abstract}

Keywords Sars2-Covid-19 $\cdot$ Interactive design $\cdot$ Emergency management $\cdot$ Hospital ship $\cdot$ Ferry

\section{Introduction}

\subsection{Pandemic situation}

As well known the COVID-19 emergency hit all the countries all over the world, also with a severe impact on the Mediterranean area, especially to areas such as Italy, France, Spain. In all those countries it is very important, for the intense critical situations developed, the capability to offer medical aid in very short terms, and we have assisted at the incredible efforts, in all countries, to realize emergency hospitals in a very short time, not only to treat emergency situations due to COVID-19, but also to release the pressure from normal

Valerio Ruggiero

vruggiero@unime.it

1 Engineering Department, University of Messina, Contrada Di Dio, 98158 Messina, Italy hospitals, taking care of other situations. It is the common opinion of several scientists that in the future the world community will probably have to face again the possibility of this pandemics spreading around.

In this scenario it is possible to define the elements of a different kind of ship, operating to help and support in those situations.

The idea of using a ship for emergency management is not new. Beyond the wartime, ideas for possible employment following earthquakes had already advanced in 1986 [1]. More recently, several studies assessed the possibility to develop model of intervention in different scenarios, such as patrol policing [2] or rescue activities [3]. Zhao et al. [4] proposed a novel approach of patrol ship configuration and suggested guidelines for fleet management while Deng et al. [5] proposed a genetic algorithm approach in order to optimize the patrol activities. Hospital ships were used in the case of humanitarian missions [6] or after disasters [7] due 


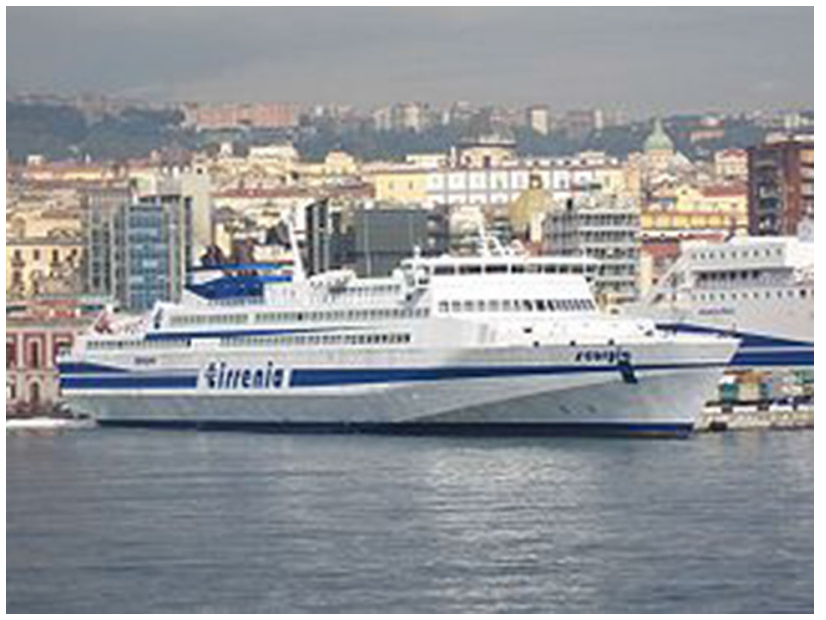

Fig. 1 The MDV 3000 at mooring (picture from web)

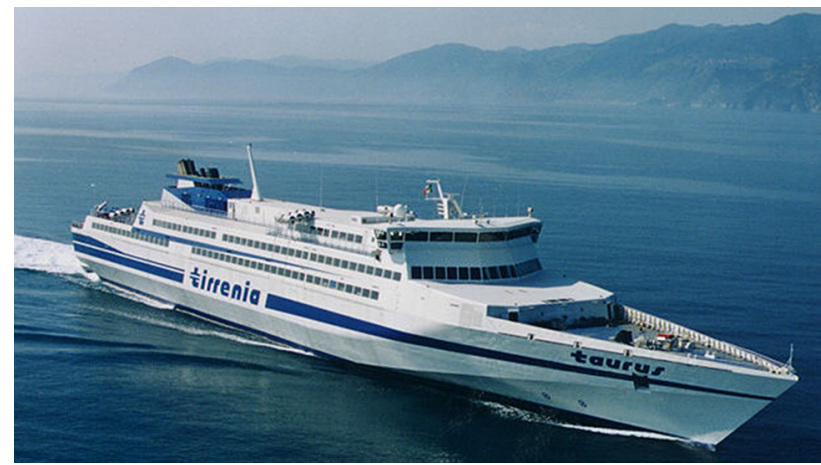

Fig. 2 The MDV 3000 at navigation (picture from web)

to their rapid intervention capacity on the site of a local emergency, generally in poor or underdeveloped Countries where the land forces were insufficient. However, there are no scientific papers relating to the use of ships in the management of pandemics or large-scale health emergencies. For the management of epidemics and pandemics, in fact, the ship can be an important resource, even in rich and developed countries, thanks to the possibility of completely isolating cases, symptomatic or asymptomatic individuals, or simply at risk, overcoming the problems observed in the isolation in hotels or hospices [8].

\subsection{Italian experiences}

In the last years Italy has been operating in different scenarios sending a fleet composed by properly called warships and also by units designed for roles more oriented to support populations.

In particular we can remember the support to Haitian population with the CAVOUR, lately the support to refuges from North Africa area, and the transportation of them in various port in Italy from Lampedusa isle.
In all the above mentioned situations it is important the speed of intervention, the capability to carry a reasonally large amount of materials, more than the military power of the ship itself, that is usually guarantee by other unit like air force or naval air force component carried by specialized ships according to requests that we are going to illustrate.

But nowadays the situation the authors are examining is completely different: a ship is needed that can perform operations of quick support in events of natural disasters (earthquakes, flooding) and sanitary emergencies, carrying a reasonable amount of first aid goods as medicaments, food, and, main topic, a ship that can operate as an emergency hospital, giving support to local installations. Additionally, the situations on several large cruise ships, with several people infected, could require the capability to realize a fast evacuation of people, from the passenger ship to an other ship, in order to reduce the risk of infection for the several thousand of passengers usually on board.

\section{Methodology and methods}

The methodology to approach the project has can be summarized with the research of the main characteristics that the ship should have and, considering the necessity to obtain a result in short time, trough the research of existing ship with matching characteristics, capable to be transformed/refitted quickly.

It is possible underline the main characteristics that this ship must have:

- possibility of a very high top speed to reach quickly the place of operations

- possibility to operate at medium speed, in order to save fuel

- possibility of quick loading roll on roll off cargo

- wide spaces for storage of food, provision

- comfortable accommodation for first aid and hospital

- possibility to carry at least 2 helicopters for medical assistance

\subsection{Operational requests to fulfill}

As described above, it's possible to summarize the main characteristics of a ship for this kind of intervention in this way:

\subsubsection{Very high top speed}

It is well known, that in an emergency situation, it is important to be on the place where the assistance is needed in a very short time.

This requires the capability to have an adequate speed, in this situation we will speak about a scenary basically located 
in the Mediterranean area or the so called "Enlarged Mediterraneum" so it is reasonable to consider necessary to sacrifice a certain amount of range in order to reach an higher speed.

A speed of 35 knots, with a peak of 40 knots of top speed can be considered reasonable.

\subsubsection{Medium speed to save fuel}

In addition to the above mentioned situation, Authors considered that could be very useful to have a medium "cruise speed" of 20 knots, that can be reached maintaining an affordable fuel consumption and using (that basically means adding hours of work) a propulsion system easy to maintain and repair.

\subsubsection{Roll on-roll of cargo}

Particularly important it is to move easily and quickly "rollon roll-off" cargoes, that can be composed by military vehicles, ambulances, commercial trucks with food, medical aid, building materials etc.

So the deck of the ship must be strong enough to support heavy loads and it is necessary to have enough space for easy manoeuvring.

These characteristics must also consider that can be impossible to moor the ship in a traditional way, with the transom against the pier, so it is needed to have also a side door in case of side mooring.

\subsubsection{Storage for cargo}

In this situation it is important, as already said, to have room to carry aid, food, etc., so the space must be prepared to carry single items already packed to be distributed.

\subsubsection{First aid, hospital, recovery}

The above mentioned emergency situations can require to host a large amount of people, and to quickly transfer them away from the emergency situation. It is important to have enough space for First Aid, for an Emergency Hospital, and also for simply for hosting and accommodating people.

It is important to underline that the basic concept of the design, was to realize a ship, possible using an existing ship, in order to save time, and get an unit with multipurpose capabilities to give a fast, immediate help in critical areas.

The ship must also have the capability of a "hospital ship", with basically on board two separated areas: one "Intensive care unit" with all the technical items needed to face contagious diseases and an other area to offer normal hospital assistance. In this way the possibility to operate at both levels according to the need of the area of interest will be guaranteed.
It is obvious that a real hospital ship such as the USNS Mercy or the Spanish "Esperanza del Mar" will offer much more comfort; in the same manner a complete cargo ship will be able to carry much more load, but the Authors's intention was to reuse an existing ship at an affordable cost.

\subsubsection{Helipad}

An helipad for touch and go of 2 small or 1 large helicopter must be provided on board.

\subsection{Case study—existing project to modify}

The deal of this work is considering all the above explained necessities, to suggest a solution that could fulfil all of them, using also something that could be available in a short time.

In the'90eis in Italy four ships called MDV 3000 m (Figs.1, 2) were built by the Fincantieri, for passenger and cargo transportation. Two units of those ships were sold for demolition, but the other two are actually operating in Mediterranean area for passenger transportations.

The authors want consider those ships for several reasons:

(1) The fact that 2 ships are actually operating could save time in order to operate a new transformation.

(2) The main characteristics of the proposal type of ship (speed, Ro-ro capacity, etc.) have been selected regarding the operational need, so the use of the existing project, even in case of a new construction could realize an interactive approach among new needs and already existing project, enhancing the possibility of use a series of informations and project data to obtain best result.

\section{Main data:}

Hull: Steel.

Superstructure: Alluminium Alloy.

Length: $145 \mathrm{~m}$.

B max: $22 \mathrm{~m}$.

Draft: $4 \mathrm{~m}$.

Propulsion: 2 Rolls Royce Ka MeWa waterjet S180 and 2 S140 side.

Engines: 2 TAG LM 2500 for $21,000 \mathrm{~kW}$ each +4 diesel MTU 20V1163 for $6500 \mathrm{~kW}$.

Passengers. 1700.

Vehicles: 450 cars or 130 cars +100 trucks (44 t. each).

Payload: $1200 \mathrm{t}$.

A previous work on these ferries [9] suggested a possible transformation as support ship.

The present paper considers a further modification inspired by the COVID-19 pandemic.

The following pictures (Fig. 3 and Fig. 4) show the original General Arrangement, using images published on Internet and on various magazines: 

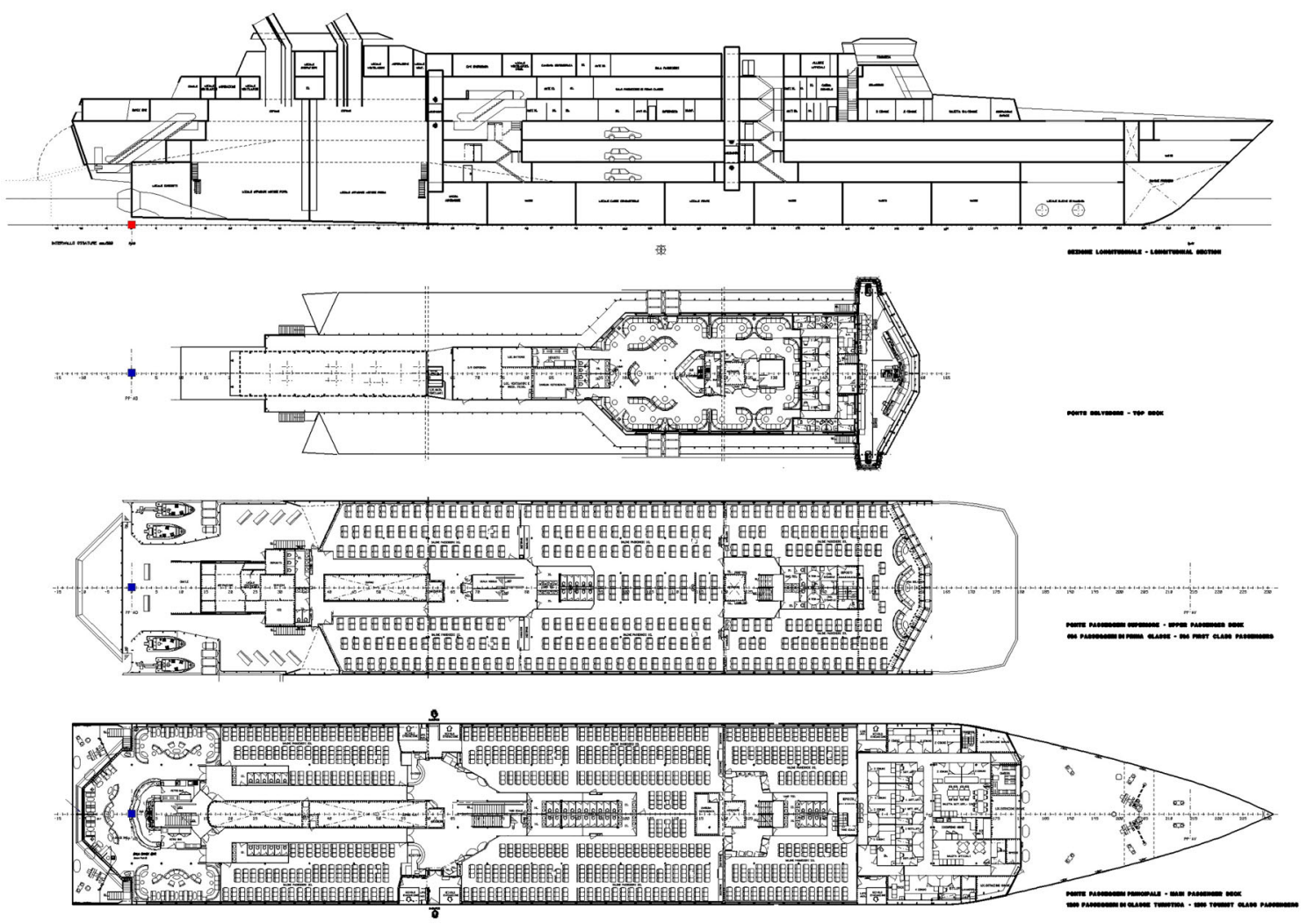

Fig. 3 General arrangement of upper decks (picture from web)
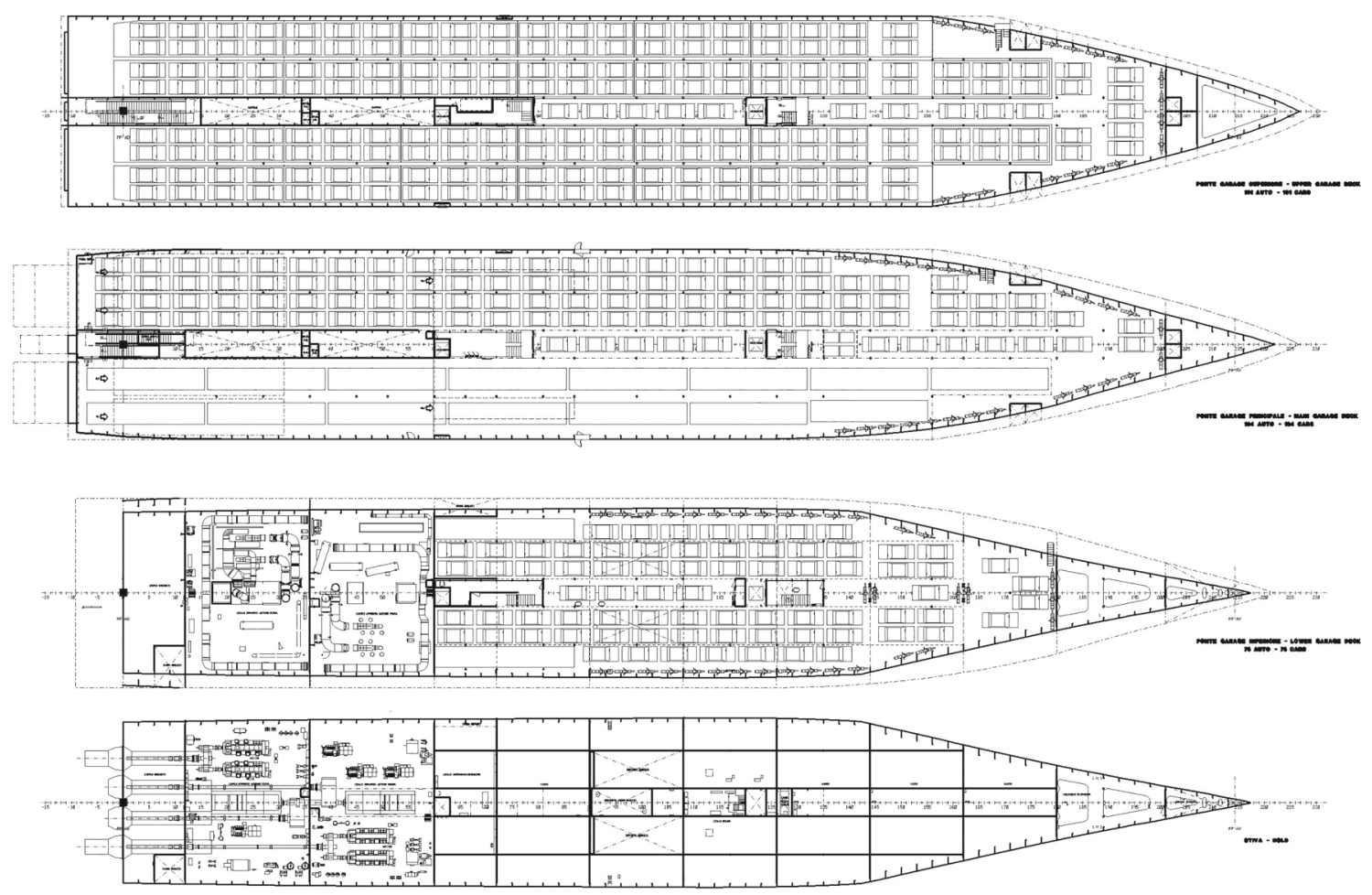

Fig. 4 Cargo decks (picture from web) 


\section{Case study-results and discussion}

The authors studied a proposal with an high degree of interactivity among several aspects of the design, and the possibility to realize the modifications in a short time.

\subsection{Propulsion}

The Authors started from the examination of the propulsion system. It is important to remind that with the actual propulsion system the ship can reach a speed of 40 knots operating with the 4 diesel engines and the 2 TAG, but can also navigate at only 20 knots simply using diesel propulsion.

Considering an operational area of the Mediterranean or even the so called Enlarged Mediterranean, a speed of 20 knots is enough to reach any operational scenario in less than 4 navigations days.

The waterjets give an excellent manoeuvrability and limit the full load draft to $3.9 \mathrm{~m}$., making it possible to operate also where the final destination (mooring place) is in shallow waters.

So the Authors decided to save the original propulsion system.

The examination of the garage decks showed that they were dimensioned to support $44 \mathrm{t}$. trucks, so the only change could be the opening of one side-door (or 2 doors, one on each side) in order to make possible to disembark light vehicles easily, with the ship moored by side.

As for the General Arrangement the main considerations will be described in the follow paragraphs:

\subsection{Top and Wheelhouse deck arrangement}

It is important to obtain a helicopter landing area on the top deck, for a "touch and go" activity of medical support.

So authors designed an area on the top deck, checking the feasibility considering the possibility to install stiffeners below the deck without problem. The stability will not be effected by the weight of the helicopter and touch and go operations.

The most interactive work among design and medical needs has been performed on accommodations: considering that the ship should have a capability to operate as "people and material carrier" and also as emergency recovery for people or for their transportation, authors decided to separate the areas of each deck to get main vertical zones, not only for the firefighting aspect, but mainly to have a separation area among different usage areas. This in order to guarantee the possibility to have proper disinfections and also to realize and maintain the areas with "negative pressure" to avoid contaminated air from the various hospitalization parts.

In fact, in order to destinate a part of the ship as hospital, also for infective diseases, all this area must be completely separated, in terms of ventilation systems, treatment of black and grey waters, etc. from any other part of the ship.

In all the General Arrangement Figure, the red colour will be used to show the parts of the ship completely renewed.

The wheelhouse deck, as showed in Fig. 5, will be modified to obtain accommodations for operators, in double bed cabins to support to general organization of the ship (Fig. 6).

\subsection{Main and Upper deck arrangement}

These are the most important decks of the ships.

The upper deck has been dedicated completely to the Hospitalization of people, starting from aft to fore, in order to realize as much "physical separation" as possible from infected people.

In terms of design and interactivity among the ship systems, this solution offers the possibility to install all the new machineries and piping on the aft part of the upper deck in order to minimize the impact and make these systems subject to easy maintenance. In this way operators and technicians can minimize contacts with hospital area. There is also an historical interesting note in this solution: in old sail ships, the "Lazzarettos" for the sick people were in the aft parts of the ship, the "downwind" parts, in order the give a natural ventilation with clean air flowing from healthy crew to sick people.

Furthermore in the decks directly above and below the hospital areas are not located spaces with fire risk: the cooking area is on the main deck but far from the hospital. In this way all the fireinsulation (A-60 for those areas) can be realized offering a higher degree of protection.

As stated at the beginning, the authors didn't aim at design a hospital ship, but a "support ship", so all the accommodations are studied to offer a first aid solution.

The area of "Intensive care unit" is studied to offer at least 10 beds, it is important to remind that, at the beginning of the Covid emergency, the Germany Health System was credited of a ration of places/population of about $1 \mathrm{bed} / 3000$ people; other countries, with efficient sanitary systems like Italy or France were credited of $1 \mathrm{bed} / 8-10.000$ people. With this ratio an accommodation for 10 beds, can be considered as serving for a first aid to $30.000 / 100.000$ people.

The authors have studied an interactive and multidisciplinary approach to the project, examining some data about the project of an Hospital ship [10] and also the data from World Health Organization [11] to obtain parameters for the arrangement of Hospital accommodations.

According to the literature about the importance of room ventilation in infective diseases $[12,13]$ the authors modified all the interiors with the realization of separations among different environments, in order to give the possibility to install ventilation systems capable to realize an appropriate pressure gradient to avoid contamination. An important aspect 

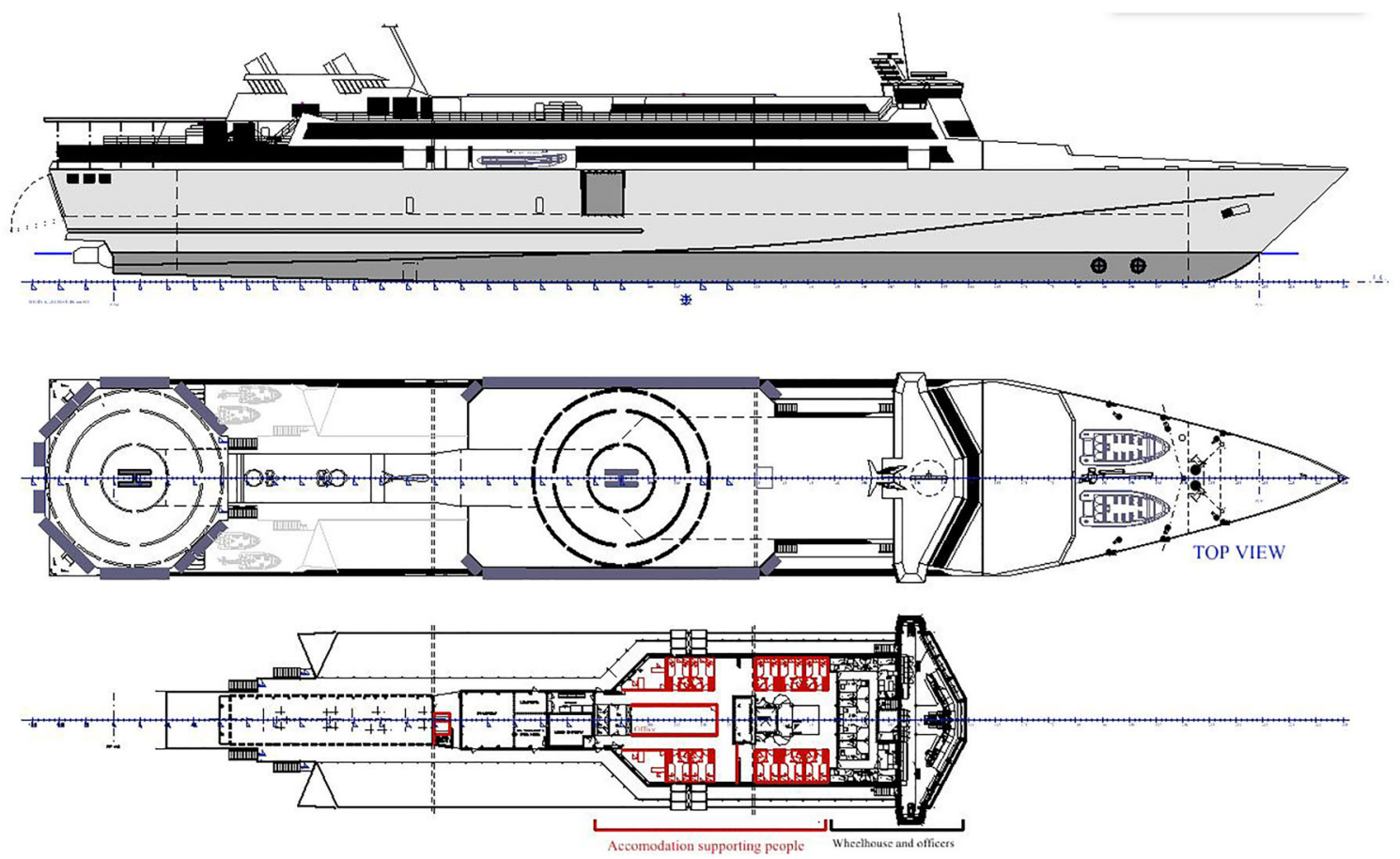

Fig. 5 Proposal transformation wheelhouse deck
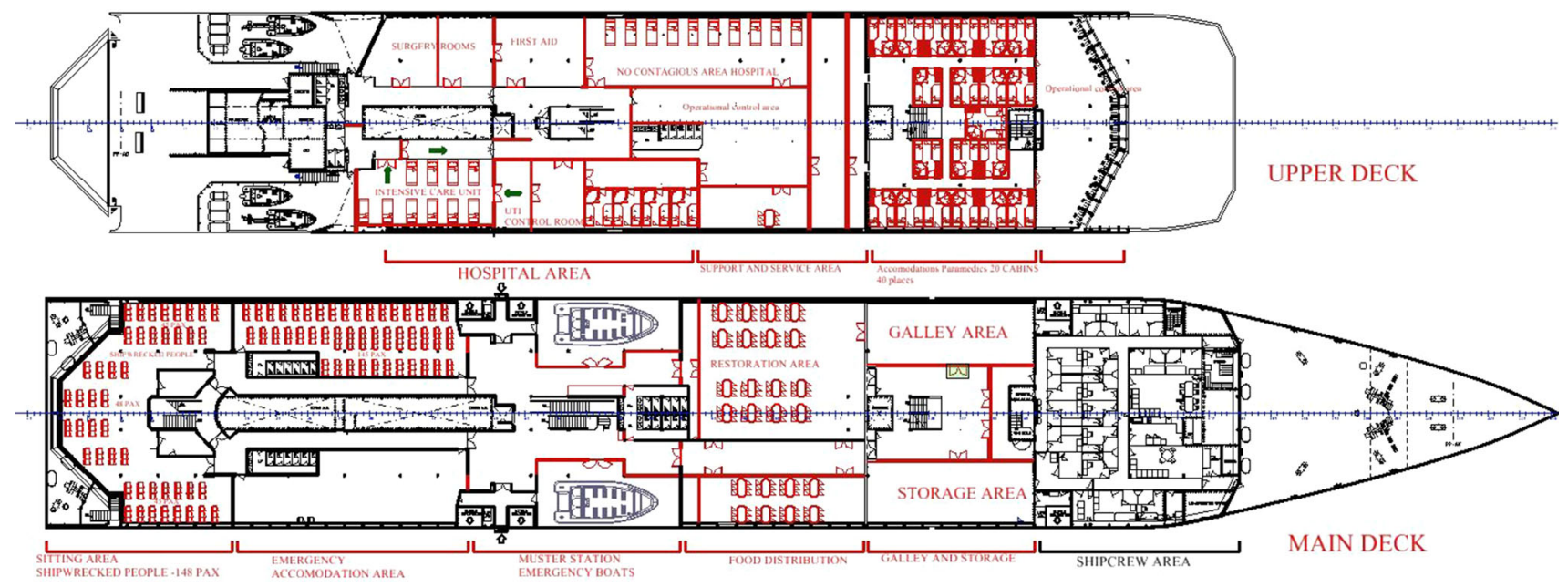

Fig. 6 Arrangement of Upper deck and Main deck

and special care must be dedicated to the exhaust of the ventilation areas, that must be conveyed in a safe part of the ship, preferably below water level to the avoid risk of contaminations.

All the areas must obviously be equipped with "state of art technologies" for remote control, and "remote diagnosis" in order to guarantee a total interactive approach among the ship and structures ashore.

Particularly the arrangement of the intensive care unit on the aft part of the Upper deck has been also studied considering the need of primary therapy for COVID-19 using hi-flow Oxygen therapy, with breathing masks for patients. This therapy needs high quantity of medical Oxygen for the patients. The Oxygen can be stored in bottles and distributed to the Hospital area realizing appropriate piping system, and the Hospital position upper deck, far from accommodations, allows the realization of piping in easy way. It is possible install a storage area on the garage deck, to provide an easy carrying of the new bottles by trucks.

The authors want also to underline the possibility for the ship to operate as a completely independent unit, producing on board a quantity of high quality Oxygen. In this case a 


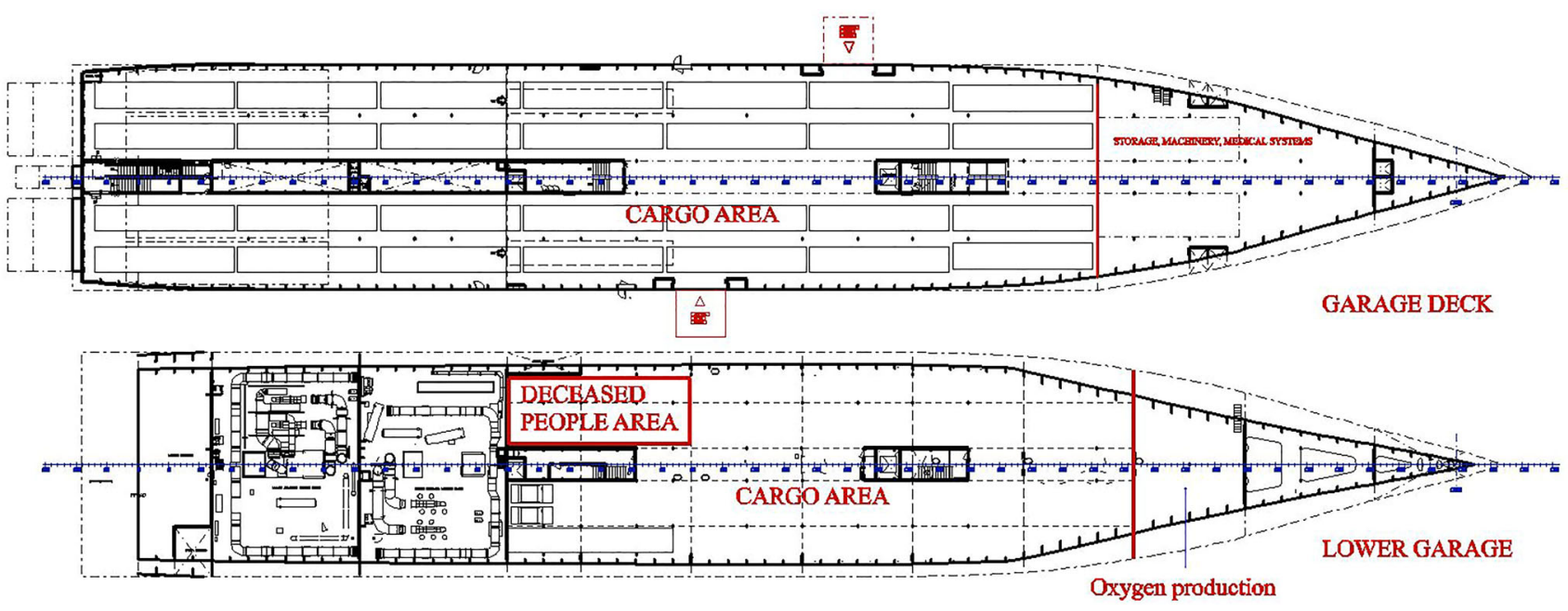

Fig. 7 Arrangement of garage deck and lower garage deck

solution with cells $[14,15]$ could be adopted on the lower garage deck (Fig. 7), using the available volume. The solution with cells is studied for submarines, in order to minimize the occupied volume.

The description of the GA, can show the possibility to modify the other areas of upper decks, to obtain more beds.

The fore part of the Upper deck can then be dedicated to the accommodations of medics and paramedics.

Obviously these accommodations must be realized in a way to give comfort and possibility to avoid infections, so the General arrangement must be considered as a proposal, and at the lowering of seriousness of pathologies treated the amount of patients treated on board can be enhanced requiring less assistance.

As parameter for the present proposal, the authors assumed a ratio of 1:1 for patients/Hospital staff, considering then to have 10 UTI beds +40 normal beds, and a corresponding accomodation of 40 people as medical staff and other 40 as "Humanitarian help and support" people.

The Main deck, in the study of the Authors, will operate as supporting deck: in case of evacuation there is a large area dedicated to 140 seating places, plus other 96 additional on left side.

A part has been dedicated to "emergency sleeping area" easy to be divided for woman and men, in case of old people, pregnant women, basically people needing a more comfortable accommodations.

Considering the various scenarios, in this study a large amount of space is left free, in order to have the possibility to embark for emergency more people than the expected, in order to give them a shelter.

Obviously according the emergency dotations to a maximum number of people.
In effect, was Author's intention to follow a line of "modularity" for the General Arrangement of the ship. In this way the ship can be quickly adapted to different scenarios.

The last part of this deck is for accommodation dedicated to the crew of the ship, and there is no need of a refitting in this area, except for normal maintenance required by the interiors.

\subsection{Garage decks}

The garage decks are one of the most interesting areas, in terms of interactivity with other aspects of technology: the amount of space allows to realize a series of support systems for the various activities of the ships. The first changes in the garage decks, were the two side doors, for easy movement of light vehicles.

But it is important to remind that the decks were structured to carry truck of $44 \mathrm{t}$. each, and with an height of $4 \mathrm{~m}$.

So it is possible to use the decks to embark also ambulances or heavy trucks of medical aid, or a complete dismountable hospital, to be mounted by the Army in whichever area, close to the ship or far, enhancing the capability of support.

As it is possible to see, the area of the vehicles decks is very large, so it is possible to use them for embarking vehicles or general loads. It could also be possible to reuse some part for accommodations for shipwrecked people or refugees, even if authors preferred not to consider this opportunity, and considering this proposal as a mean to have basically a ship capable to carry quick large amount of vehicles of aids on containers on wheels and/or independent way of transport.

The Authors already described the possibility to adapt part of the Lower garage as area for production and stowage of Oxygen for therapy (a patient can need several litres of Oxy- 
gen on a daily basis). The selected area is on the fore part of the lower deck, to make possible realize the necessary ducts for ventilation/providing air.

An other area of the lower garage, could be realized to house the bodies of deceased people, in condition of sanitary security (low temperature cells) to avoid contaminations.

\subsection{Impact on displacement}

A similar refit must consider any changes in the structure and weight and stability of the ship, so authors checked the situation regarding this aspect.

As well known the MDV 3000 were built by Fincantieri with attention to the weight, in order to reach the high speed promises.

The Authors considered that all the furniture in the area to be remodelled will be dismounted and the new ones will be realized with different materials.

The initial weight of the passengers and personal effects (1784 people) was close to $170 \mathrm{t}$.

In Author's intentions the total capability of the ship can be considered as follows:

100-120 people carried as "Staff": Medicians, Operators, plus 60-100 patients (depending on the arrangement of the available areas, 100 refugees in Seats or accommodations).

In total, according to the SOLAS values for people weight $(75 \mathrm{~kg})$ about $40 \mathrm{t}$ of "weight" to carry as for people.

This mean a margin in weight of more than 130 t., largely enough to compensate the weight added by the new accommodations.

It is also important to consider that the ship will operate in two different ways:

On going to the place of intervention, the ship will be carrying goods, truck etc. Leaving the place of intervention and moving away refugees and other members of staff, most part of the load will be consumed or left behind.

\subsection{Economical/cost evaluation}

It is not easy to estimate the cost of the transformation, basically because the available literature is regarding the construction costs of an hospital ashore, with a differences in the aim $[16,17]$.

In this case, moreover, there is to consider that for Emergency situation the cost cannot be evaluated from the traditional point of view of the possible future income, but only as "emergency solver".

However, the authors examined some data for the construction of Passenger Ships, where the cost of accommodations can be usually estimated in 6-10.000 euro for each square meter, and the cost of a new similar unite for Coast Guard, completely built, where for a $100 \mathrm{~m}$ ship the cost is around 80 millions of euros.
With this data is possible to estimate the cost for transformation in about 40 millions euro for ship.

\section{Conclusions}

As it is possible to see from the General Arrangement, the new idea is not to make a "completely new " kind of ship, but to smartly reuse something that has been already built or designed, making an interaction among several different needs: fast aid in case of pandemic, need to offer medical support to critical areas where there is not an hospital large enough for people exceeding the 10-15 units, provide immediate transportation of trucks with massive amount of goods, medicins etc., in order to develop an instrument that, travelling by the sea, can operate in Mediterranean in this study, and obviously anywhere in the world.

The main point of the study, that consider a "case study" of an unit, already used, is to underline the advantages of a new typology of approach, where the interactivity among the needs required by a completely new world emergency and the medical aspects can be applied to a typology of ships, the Ro-Ro ferry, that can be readapted to offer easy efficient support.

The main limitation that can appear at the beginning, the limited amount of beds, can be compensated by the fact that the ship is an independent system, capable to move, and in case of Ro-Ro ferries, the ship can operate also carrying huge amount of payload, as medical aid etc., offering also support to the ashore facilities in case of their overload.

The Authors considered the limitations of using as starting point a ship of "only" $145 \mathrm{~m}$ of length, obviously a Ro-Ro Ferry $200-250 \mathrm{~m}$. long and a larger tonnage could host an higher amount of patients, but the advantage of a ship of $145 \mathrm{~m}$, with consequent limited draft, is the possibility to moor, as independent unit, in small harbours, or small islands, where usually the Sanitary presidium is limited and can be easy overloaded by a pandemic event.

\section{References}

1. Reitherman, R.: How to prepare a hospital for an earthquake. J. Emerg. Med. 4, 119-131 (1986). https://doi.org/10.1016/07364679(86)90075-2

2. Carter, D., Moizer, J.D.: Simulating the impact of policy on patrol policing: introducing the emergency service incident model. Syst. Dyn. Rev. 27, 331-357 (2011). https://doi.org/10.1002/sdr.465

3. Li-bo, Y.: Study of maritime traffic patrol and rescue ships configuration amount. Sh. Eng. 35(2), 19-22 (2013)

4. Zhao, F.B., Wang, Y., Xie, X.L.: A novel approach of patrol ship configuration and fleet planning. Appl. Mech. Mater. 744-746, 1761-1766 (2015). https://doi.org/10.4028/www. scientific.net/AMM.744-746.1761 
5. Deng, S., Wu, Q., Wang, Y.: Maritime patrol ship site location optimization in Yangtze river based on genetic algorithm. In: ICTIS 2013, pp. 2010-2016. American Society of Civil Engineers, Reston, VA (2013)

6. Hameed, J.M., McCaffrey, R.L., McCoy, A., Brannock, T., Martin, G.J., Scouten, W.T., Brooks, K., Putnam, S.D., Riddle, M.S.: Incidence, Etiology and Risk Factors for Travelers' Diarrhea during a Hospital Ship-Based Military Humanitarian Mission: Continuing Promise 2011. PLoS ONE 11, e0154830 (2016). https://doi.org/ 10.1371/journal.pone.0154830

7. van Ommeren, M., Saxena, S., Saraceno, E.: Aid after disasters. BMJ 330, 0506223 (2005). https://doi.org/10.1136/sbmj.0506223

8. Cohen, C.I., Sokolvsky, J.: Social engagement versus isolation: the case of the aged in SRO hotels. Gerontologist. 20, 36-44 (1980). https://doi.org/10.1093/geront/20.1.36

9. Ruggiero, V., Guglielmino, E., Orteca, V., Cucinotta, F.: A new idea for an Italian fast support ship for peacekeeping and assistance in case of events in Enlarged Mediterraneum scenario., HSMV (High Speed Marine Vehicles)—Napoli 25-27 maggio 2011. pp 1-6 ISBN 9788890611209 (2011)

10. Polmar, N.: The Naval Institute Guide to the Ships and Aircraft of the U. S. Fleet, Eighteenth Edition, Naval Institute Press, Annapolis, MD, (ISBN 1-59114-685-2), pp. 264-266. (2005)

11. AA.VV.: Clinical management of severe acute respiratory infection (SARI) when COVID-19 disease is suspected: Interim guidance, AA.VV., World Health Organization (2020)

12. Hoffman, P.N., Weinbrenb, M.J., Stuartc, S.A.: A practical lesson in negative-pressure isolation ventilation. J. Hosp. Infect. 57(4), 345-346 (2004)
13. AA.VV.: Isolation Rooms \& Pressurization Control, Penn State Department of Architectural Engineering, The Pennsylvania State University (2008)

14. Arkilander, W.N., Molter, T.M.: Oxygen generator cells design for future Submarines, Hamilton Standard division of United Technologies corp., (1982)

15. Giddey, S., Ciacchi, F.T., Badwal, S.P.S.: High purity oxygen production with a polymer electrolyte membrane electrolyser. J. Membr. Sci. 346(1), 227-232 (2010)

16. Negrini, D., Kettle, A., Sheppard, L., Mills, G.H., Edbrooke, D.L.: The cost of a hospital ward in Europe: is there a methodology available to accurately measure the costs? J. Health Org. Mgt. (2004). https://doi.org/10.1108/14777260410548437

17. Bai, G., Zare, H.: Hospital Cost Structure and the Implications on Cost Management During COVID-19. J. Gen. Intern. Med. 2020 Sep; 35(9):2807-2809. https://doi.org/10.1007/s11606020-05996-8. Epub 2020 Jun 30. PMID: 32607935; PMCID: PMC7326305.

Publisher's Note Springer Nature remains neutral with regard to jurisdictional claims in published maps and institutional affiliations. 